\title{
Inhibition of Spinal Reflexes by Paramedian Reticular Nucleus
}

\author{
C. Y. CHAI, ${ }^{1}$ Y. F. LIN,$*$ H. Y. WANG, * W. C. WU, $*$ \\ C. T. YEN, $\dagger$ J. S. KUO $\ddagger$ AND M. J. WAYNER $\S$ \\ *Institute of Biomedical Sciences, Academia Sinica \\ †Department of Zoology, National Taiwan University \\ $\ddagger$ Department of Medical Research, Taichung Veterans, General Hospital, Taiwan, Republic of China \\ $\S$ Division of Life Sciences, University of Texas at San Antonio
}

Received 2 April 1990

\begin{abstract}
CHAI, C. Y., Y. F. LIN, H. Y. WANG, W. C. WU, C. T. YEN, J. S. KUO AND M. J. WAYNER. Inhibition of spinal reflexes by paramedian reticular nucleus. BRAIN RES BULL 25(4) 581-588, 1990. - The inhibitory actions of the paramedian reticular nucleus (PRN), and its neighbouring structures, i.e., midline raphe nuclei (MRN) and dorsal medullary depressor area (DMD) on the knee jerk (KnJ) and crossed extension movement (CEM) induced by central sciatic stimulation and on the L5 ventral root response (EVRR) evoked by central tibial stimulation, were studied in cats under urethane $(400 \mathrm{mg} / \mathrm{kg}$ ) and alpha-chloralose (40 mg/ $\mathrm{kg}$ ) anesthesia alone, IP or further paralyzed with atracurium besylate $(0.5 \mathrm{mg} / \mathrm{kg} / 30 \mathrm{~min})$, IV. Electrical stimulation of the above areas with rectangular pulses $(80 \mathrm{~Hz}, 1.0 \mathrm{msec}, 100-200 \mu \mathrm{A}$ ) decreased systemic arterial blood pressure (SAP) in an average value of: $36 \pm 3 \mathrm{mmHg}$ for PRN; $19 \pm 2 \mathrm{mmHg}$ for MRN; and $23 \pm 3 \mathrm{mmHg}$ for DMD. The KnJ and CEM were almost completely suppressed by simultaneous PRN stimulation. The EVRR, including mono- and polysynaptic spinal reflexes with transmission velocity from 10 to $60 \mathrm{~m} / \mathrm{sec}$ or above, were also suppressed. MRN stimulation only inhibited the $\mathrm{KnJ}$, CEM and polysynaptic spinal reflexes with transmission velocities between 25 and $60 \mathrm{~m} / \mathrm{sec}$, but facilitated spinal reflexes with conduction velocities below $10 \mathrm{~m} /$ sec. On the other hand, DMD stimulation resulted in small suppression of $\mathrm{KnJ}$, CEM and inhibition of polysynaptic spinal reflexes with conduction velocities between 25 and $60 \mathrm{~m} / \mathrm{sec}$. Even though MRN and DMD partially inhibited polysynaptic spinal reflexes, the magnitude of such inhibition was much smaller than that produced by PRN ( $-20 \%$ and $-22 \%$ vs. $-48 \%$ ). The above-mentioned PRN effects on SAP and EVRR persisted in chronic animals decerebellated 9-12 days before. In addition, microinjection $(200 \mathrm{nl})$ of sodium glutamate $(1 \mathrm{M})$, DL-homocysteic acid $(0.05 \mathrm{M})$ or kainic acid $(0.047 \mathrm{M})$ to PRN also decreased KnJ, CEM and EVRR. The present results suggest that the PRN, containing both cell bodies and fibers projected from elsewhere, in addition to its inhibitory effects on the autonomic nervous system, also depresses the somatic nervous system, including mono- and polysynaptic motoneuronal pools. This inhibitory action of the PRN is excrted independently of the efferent and afferent connections of the cerebellum.
\end{abstract}

Paramedian reticular nucleus Knee jerk Crossed extensor movement Evoked ventral root response Decerebellation

IN a previous study (7) we demonstrated that spinal reflexes, i.e., knee jerk and crossed extension were affected by visceral activity; facilitation during visceral afferent stimulation and inhibition during visceral efferent stimulation. In a more recent study (8) we demonstrated extremely potent inhibitory functions, both visceral and somatic, of the paramedian reticular nucleus (PRN) in the caudal medulla. Although stimulation of the PRN produced only mild decreases in systemic arterial blood pressure (SAP, 20-40 $\mathrm{mmHg}$ ), its activation antagonized, or even abolished, the marked SAP increase of over $100 \mathrm{mmHg}$, induced by direct brain stimulation. Its stimulation also effectively delayed the occurrence and reduced the SAP increment resulting from asphyxial anoxia or an increase in intracranial pressure. Furthermore, PRN stimulation also suppressed the violent muscular convulsion, a somatic effect, in the initial stage after a high IV dose of picrotoxin, a gammaaminobutyric acid (GABA) antagonist. The latter action suggests that PRN might also exert a potent inhibitory action on spinal reflexes. Since other areas in the medulla, such as the midline raphe nuclei (MRN) and the dorsal medulla depressor area (DMD), integrate visceral functions including depressor effects, it would be interesting and significant to determine if these visceral inhibitory areas also possess inhibitory effects on somatic functions,

The PRN and the cerebellum are interconnected. When horseradish peroxidase (HRP) is injected into the PRN, retrogradely labeled neurons have been found in many areas, including the cerebellum (18). In addition, all three subdivisions of the PRN (dorsal, ventral, and accessory groups) were found to send projections to the cerebellum $(3,4)$. Thus, the PRN and the cerebellum are reciprocally innervated. The PRN is considered to be one of a number of precerebellar relay nuclei. It is different both morphologically and functionally from other parts of the

\footnotetext{
${ }^{1}$ Requests for reprints should be addressed to Professor C. Y. Chai, Institute of Biomedical Sciences, Academia Sinica, Nankang 11529, Taiwan, Republic of China.
} 
TABLE 1

EFFECTS OF PRN, MRN, AND DMD STIMULATION ON THE EVOKED KNEE JERK REFLEX (KnJ) AND CROSSED EXTENSOR REFLEX MOVEMENT (CEM) IN CERFBELLUM-INTACT CATS

$\%$ Change of Reflexes

Brain

\begin{tabular}{lcc} 
Stimulation & KnJ & CEM \\
\hline PRN & $-93 \pm 5^{*}$ & $-99 \pm 1^{*}$ \\
MRN & $(9)$ & $(9)$ \\
& $-70 \pm 6^{*}$ & $-67 \pm 9^{*}$ \\
DMD & $(11)$ & $(11)$ \\
& $-12 \pm 4$ & $-4 \pm 3$ \\
& $(5)$ & $(5)$
\end{tabular}

All results are represented as a mean value \pm S.E.M. Numbers in parentheses indicate the number of points electrically stimulated. Asterisks indicate percent changes of $\mathrm{KnJ}$ and $\mathrm{CEM}$ before and during brain stimulation that are significantly different: $* p<0.001$ calculated by paired Student's t-test.

medullary reticular formation $(2,4,30)$. Furthermore, the PRN might be a site of inhibitory interactions between projections from the fastigial nucleus of the cerebellum and the carotid sinus nerve acting on SAP (36). Increases or decreases in SAP induced by stimulation of the fastigial nucleus and carotid sinus nerve, respectively, were abolished after PRN stimulation. It is important to determine if the modulatory effect of PRN on somatic function is mediated through the cerebellum.

The purpose of the present study was (a) to determine if the inhibitory effect on spinal reflexes is specific to the PRN and not other depressor areas and (b) to determine if the cerebellum is involved in the mechanism of PRN inhibition of spinal reflexes.

\section{METHOD}

Experiments were performed on 59 adult cats of either sex, weighing between 1.7 and $3.4 \mathrm{~kg}$. Thirteen werc chronically decerebellated 9 to 12 days before under pentobarbital anesthesia. Experiments were performed under intraperitoneal urethane (400 $\mathrm{mg} / \mathrm{kg}$ ) and alpha-chloralose $(40 \mathrm{mg} / \mathrm{kg}$ ) anesthesia with artificial ventilation keeping the end-expiratory $\mathrm{CO}_{2}$ concentration at $4 \%$ and maintenance of the body temperature at $37 \pm 0.1^{\circ} \mathrm{C}(8.31)$. The right femoral vein was cannulated for drug injection and the right femoral artery was utilized for monitoring the SAP. mean systemic arterial blood pressure (MSAP), and heart rate (HR). All responses were recorded by a Gould ES 1000 polygraph.

\section{The Gross Knee Jerk Reflex (KnJ) and Crossed Extensor Movement (CEM)}

The gross KnJ and CEM were evoked by stimulating the central end of the ipsilateral sciatic nerve every $60 \mathrm{sec}$ with a 1.0 msec single rectangular pulse $(1.0 \mathrm{msec}, 0.1-1.0 \mathrm{~mA})$. The movements of the bilateral femoral extensors were monitored via force displacement transducers (Grass FT03. AC coupling) and recorded by a Gould polygraph (7).

\section{The Evoked Ventral Root Responses (EVRR)}

The anesthetized animals were further immobilized with atracurium besylate $(0.5 \mathrm{mg} / \mathrm{kg} / 30 \mathrm{~min})$, IV. The ipsilateral tibial nerve which innervates the gastrocnemius muscle was isolated. Laminectomy was performed at spinal level of L4-L6 to expose the ventral root at L5. The exposed spinal cord and nerves were covered with mineral oil. EVRRs, the compound action potential recorded from the L5 ventral root via a pair of platinum bipolar hook electrodes, were evoked by stimulating the central end of the cut tibial nerve of the ipsilateral side, through a bipolar electrode (Harvard). Rectangular pulses, $1.0 \mathrm{msec}$ duration, 200-1000 $\mu \mathrm{A}$ intensity, which was 5 to 10 times the threshold strength for evoking the responses, were applied once per second. In the experiments using excitatory amino acids for activation the threshold strength was $20-100 \mu \mathrm{A}$. The EVRRs were amplified and filtered with a WPI preamplifier (DAM $60,100-1000 \times, 300 \mathrm{~Hz}$ to $3 \mathrm{KH} L$ ) and a Gould universal amplifier. Potentials were displayed on a storage oscilloscope (Tektronix 5113), and monitored by an audio amplifier (Neurolog). All recordings were fed to a tape recorder (HP 3968A) or photographed directly from the screen of the oscilloscope with a polaroid camera. For analysis of the EVRR, the recorded data were fed to a Data 6000 signal averager to obtain an averaged area calculated from 10 reflex discharges. The tracings of the averaged area, both the fast and

TABLE 2

EFFECTS OF PRN, MRN. AND DMD STIMULATION ON THE EVOKED VENTRAL ROOT RESPONSES (EVRR)

\% Change of Different Components in EVRR

Brain

\begin{tabular}{lcccc} 
Stimulation & Group 1 & Group 2 & Group 3 & Group 4 \\
\hline PRN & & & & \\
Intact & $-40 \pm 5 \dagger$ & $-48 \pm 8+$ & $-40 \pm 6+$ & $-8 \pm 6$ \\
& $(26)$ & $(40)$ & $(40)$ & $(40)$ \\
Chronically & $-38 \pm 9+$ & $-61 \pm 6+$ & $-45 \pm 11+$ & $-11 \pm 14$ \\
decerebellated & $(25)$ & $(25)$ & $(25)$ & $(25)$ \\
MRN & $-6 \pm 8$ & $-20 \pm 7 *$ & $-4 \pm 10$ & $+26 \pm 10^{*}$ \\
& $(18)$ & $(26)$ & $(26)$ & $(26)$ \\
DMD & $-11 \pm 9$ & $-22 \pm 10^{*}$ & $-12 \pm 13$ & $+2 \pm 4$ \\
& $(7)$ & $(14)$ & $(14)$ & $(14)$
\end{tabular}

All results are presented as a mean value \pm S.C.M. Numbers in parentheses indicatc the number of points electrically stimulated, asterisks indicate changes of the respective components in EVRR during brain stimulation of each region that are statistically significant: ${ }^{*} p<0.05, \dagger p<0.001$ (paired Student's $t$-test). 

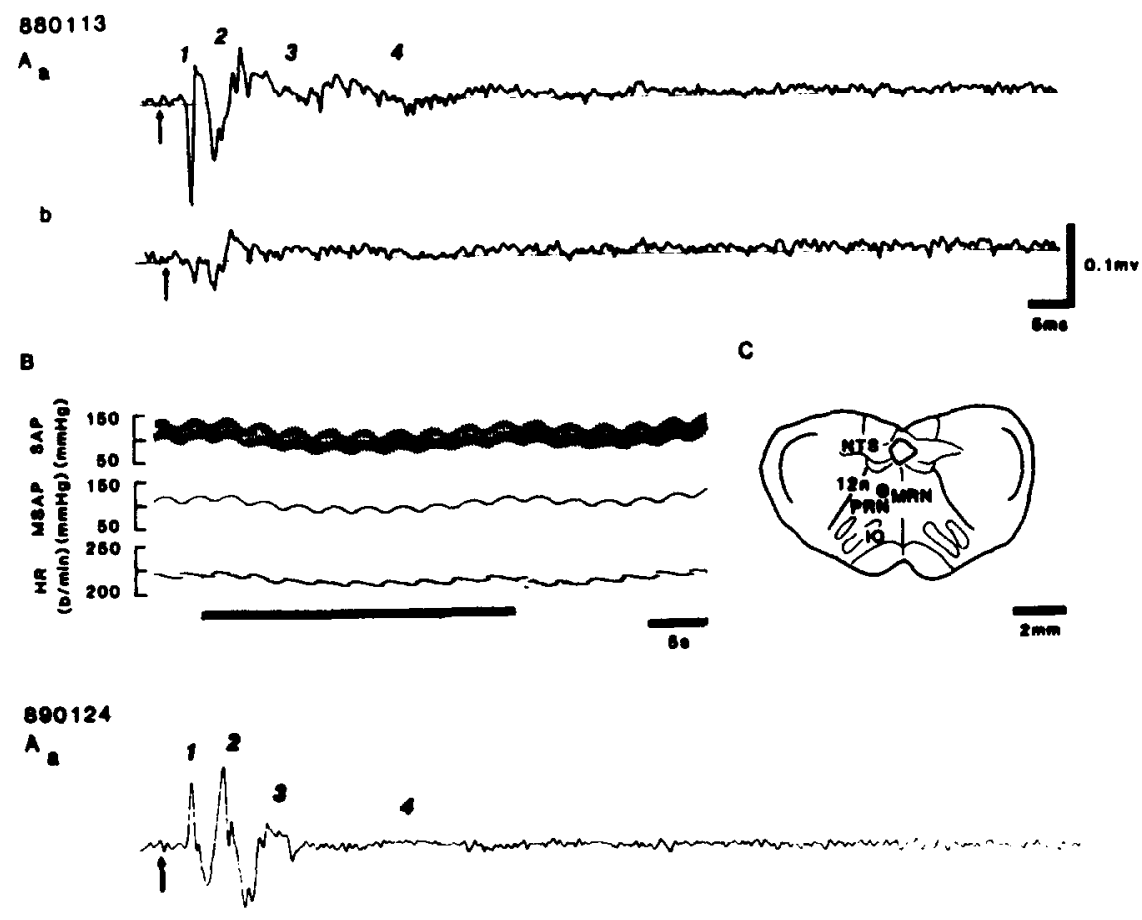

b

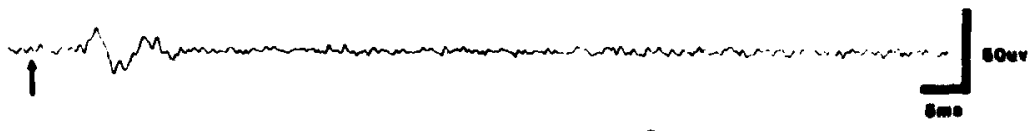

B

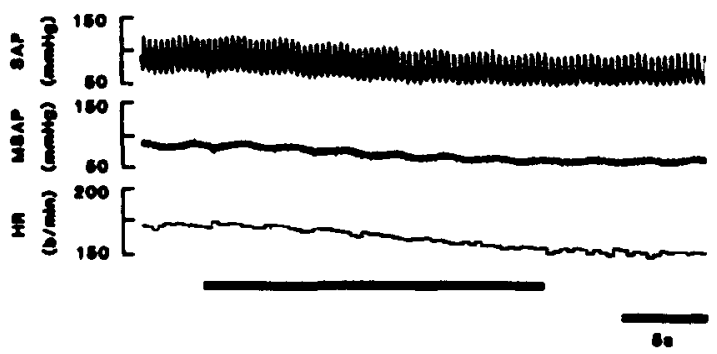

C

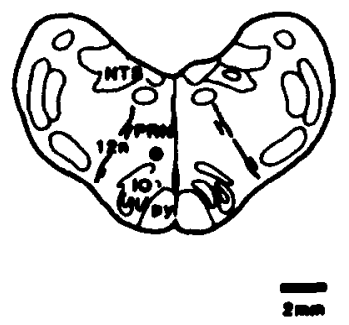

FIG. 1. Evoked ventral root responses (EVRR) before (Aa) and during (Ab) PRN stimulation in a cerebellum-intact cat (upper panels, 880113) and chronically decerebellated cat (lower panels, 890124). Note that the four components of responses, 1,2,3 and 4, classified according to their velocities of transmission were induced in both preparations. Note also that PRN stimulation $(150 \mu \mathrm{A}, 1.0 \mathrm{msec}$ and $80 \mathrm{~Hz}$ ) only produced a mild reduction of SAP but marked reduction of EVRR. For this and the following figures, the arrow indicates the onset of afferent nerve stimulation to evoke spinal reflex discharges. Tracings in B show the cardiovascular responses during PRN stimulation. Dot in C indicates the site of stimulation. Abbreviations for this and all the following figures: $\mathrm{SAP}=$ systemic arterial blood pressure; MSAP = mean systemic arterial blood pressure; $H R=$ heart rate. Abbreviations for all the histomicrographs: $5 \mathrm{SP}=$ alaminar spinal trigeminal nucleus, parvocellular division; $5 \mathrm{ST}=$ spinal trigeminal tract; $12=$ hypoglossal nucleus; $12 \mathrm{n}=$ hypoglossal nerve; $\mathrm{DMD}=$ medullary depressor area; $\mathrm{IO}=$ inferior olivary nucleus; $M R N=$ midline raphe nuclei; $N T S=$ nucleus tractus solitarius; $P R N=$ paramedian reticular nucleus; $p y=$ pyramidal tract.

slow components, were then plotted by the data averager and a plotter. In some experiments the evoked potential was expanded and displayed on the polygraph through a waveform module (Gould, $100 \mathrm{KHz}$ ).

The EVRRs induced by suprathreshold stimulation were classified into four components in accordance with their transmission velocities (nerve length between recording and peripheral stimu- lating electrodes divided by the latency of each evoked potential). They are: component 1, above $60 \mathrm{~m} / \mathrm{sec}$; component 2 , between 25 and $50 \mathrm{~m} / \mathrm{sec}$; component 3, between 10 and $25 \mathrm{~m} / \mathrm{sec}$; and Group 4 , below $10 \mathrm{~m} / \mathrm{sec}$. The paired Student's $t$-test or one-way ANOVA was used for the statistical treatment of the data and calculation of the significance of changes in the EVRR induced by stimulation of each brain area or between different brain areas. 
880114

A $\mathbf{a}$

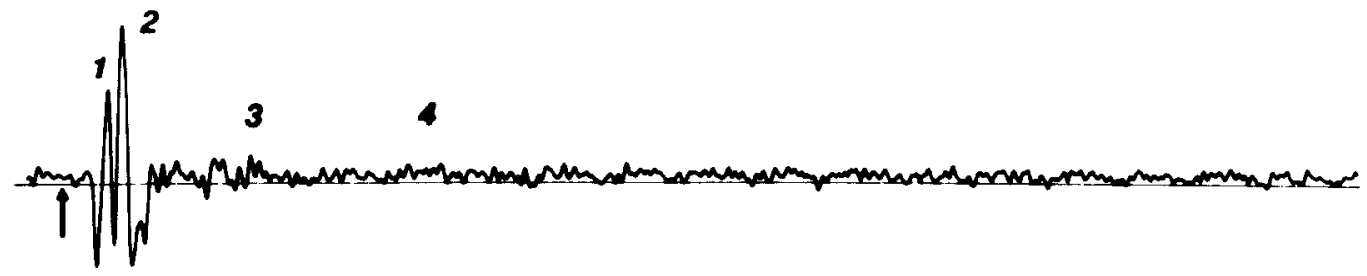

b

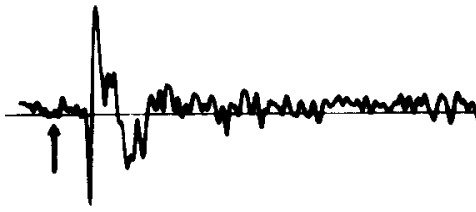

B

C

sour
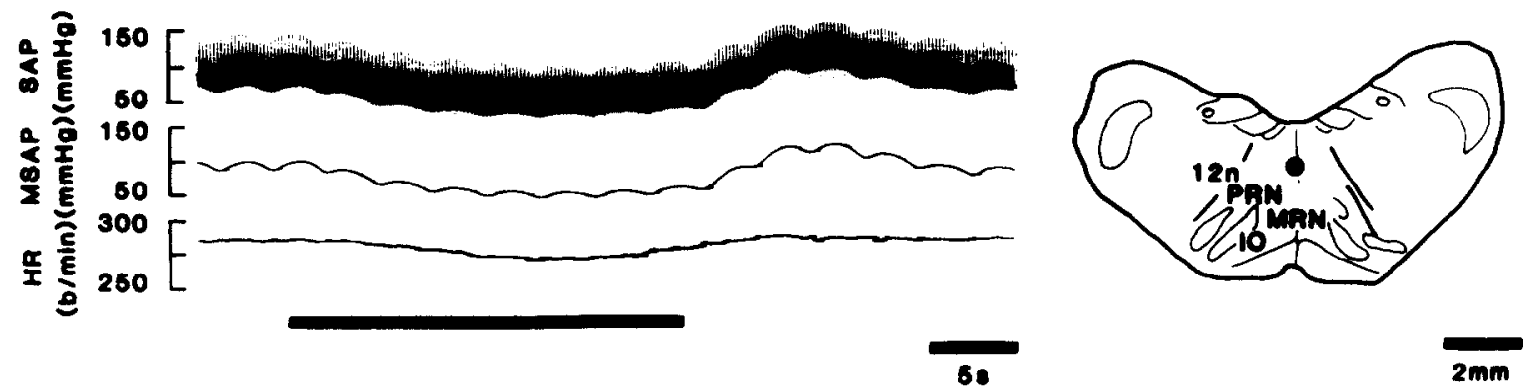

FIG. 2. Effects of stimulation of the midline raphe nuclei (MRN) on EVRR in cerebellum-intact cats. Note that MRN stimulation (150 $\mu$ A, 1.0 msec and $80 \mathrm{~Hz}$ ) only moderately reduced the EVRR component 2 despite a similar decrease in SAP. For abbreviations see Fig. 1.

\section{4}

A

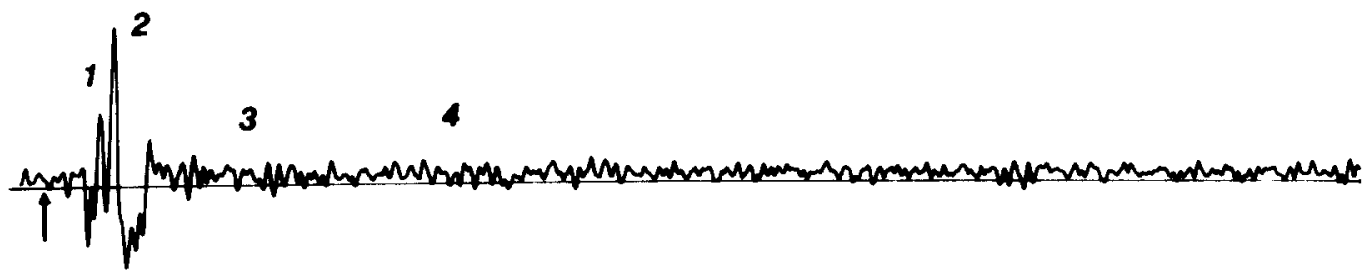

b

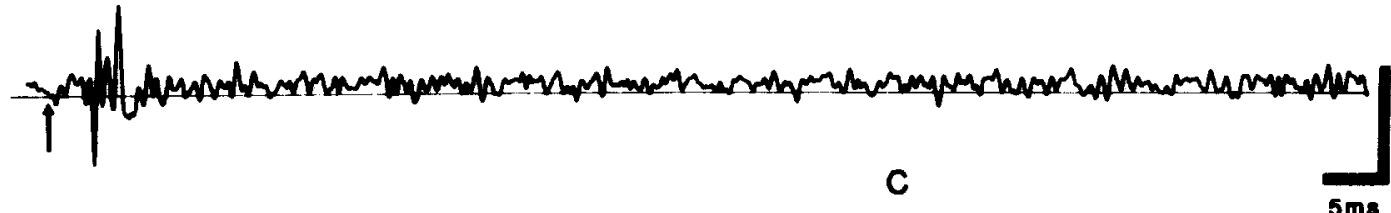

50uv

B

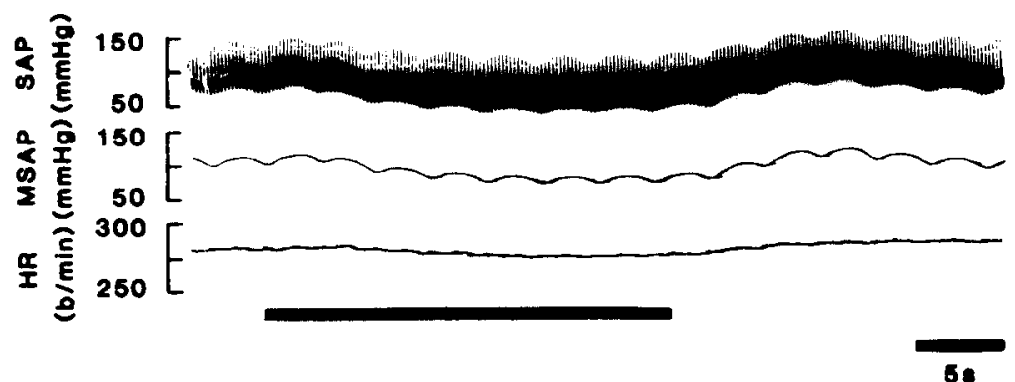

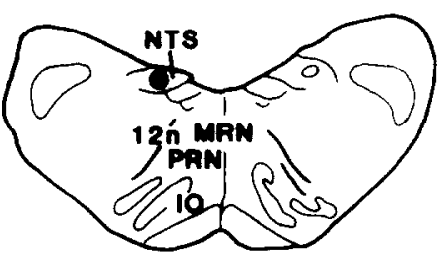

$2 \mathrm{~mm}$

FIG. 3. Effects of stimulation of the dorsal medulla depressor area (DMD) at NTS region on EVRR in cerebellum-intact cats. DMD stimulation $(150 \mu \mathrm{A}, 1.0 \mathrm{msec}$ and $80 \mathrm{~Hz})$ only moderately reduced the EVRR component 2 . For abbreviations see Fig. 1. 
891122
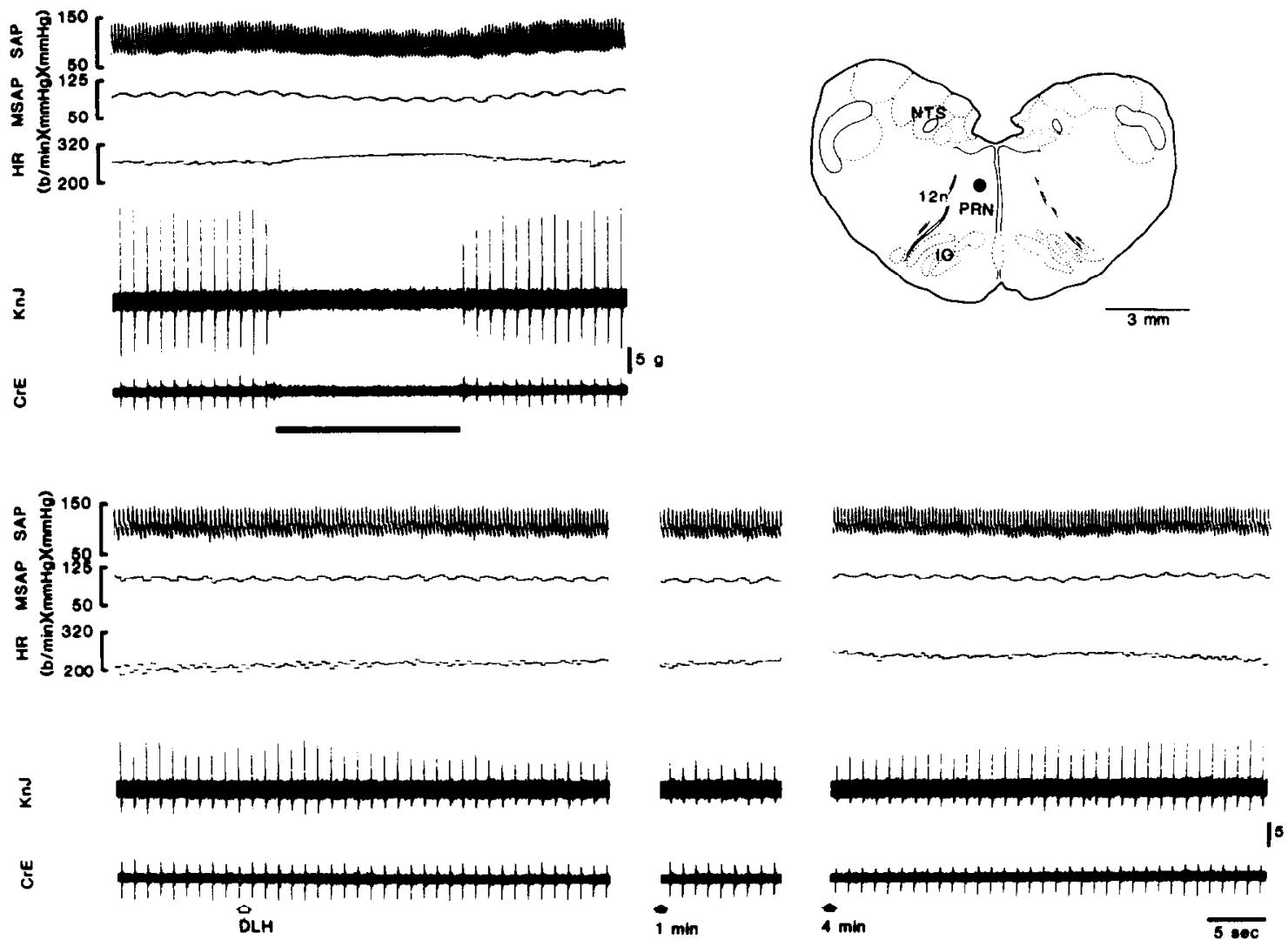

FIG. 4. Effects of DL-homocysteic acid (DLH) stimulation of PRN on the evoked knee jerk and crossed extensor movement in a cerebellum-intact cat. The reflexes were induced by stimulating the central end of the cut sciatic nerve (left) every $60 \mathrm{sec}$ with a single pulse at a threshold intensity $(100 \mu \mathrm{A}, 1.0 \mathrm{msec})$. PRN was stimulated first with an electrical current $(100 \mu \mathrm{A}, 1.0 \mathrm{msec}$ and $80 \mathrm{~Hz})$ and then followed by DLH $(200 \mathrm{nl})$. Dot in the histomicrograph shows the sites of stimulation. Note that DLH, similar to electrical stimulation produced a reduction of SAP and spinal reflexes. For abbreviations see Fig. 1.

\section{Brain Stimulation}

The medulla was exposed and stereotaxically stimulated as described previously (8). In the cerebellum-intact animals, three areas were stimulated, namely; the PRN, MRN and DMD. In chronically decerebellate animals, only the PRN was stimulated to compare the effects of PRN stimulation on spinal reflexes with that of the cerebellum-intact animal. The stereotaxic coordinates of these nuclei are: PRN, 0 to $4 \mathrm{~mm}$ rostral to obex, 0.7 to $2 \mathrm{~mm}$ lateral to midline and 2 to $4 \mathrm{~mm}$ ventral to the dorsal surface of the medulla. MRN, 0 to $2 \mathrm{~mm}$ rostral to obex, at the midline, and 1 to $5 \mathrm{~mm}$ ventral to the dorsal surface of the medulla. DMD, 2 to $4 \mathrm{~mm}$ rostral to obex, 2 to $2.5 \mathrm{~mm}$ lateral to the middle and 1 to $3 \mathrm{~mm}$ ventral to the dorsal surface of the medulla. Electrical stimulation was accomplished by means of a bipolar coaxial electrode (Rhodes Med. Instruments, SN-100), inserted at a $34^{\circ}$ angle into the medulla. Rectangular pulses were delivered by a constant current unit connected to a Grass S-88 stimulator. In some experiments, monopolar electrical stimulation and semimicroinjection (100-200 nl) of monosodium glutamate (Glu, 1 M), DL-homocysteic acid (DLH, $0.05 \mathrm{M}$ ) or kainic acid (KA, $0.047 \mathrm{M}$ ) (all prepared in saline, at $\mathrm{pH} 7.4$, with $0.5 \%$ fast green) were administered to the same point of the brain tissue through a 30-gauge electrode tube with a Hamilton syringe as described previously $(8,31)$. Stimulation consisted of trains of $1 \mathrm{msec}$ pulses, $80 \mathrm{~Hz}$, for a duration of $15 \mathrm{sec}$. Intensity varied from $100-200 \mu \mathrm{A}$. The chemical stimulation sites were determined by the ejection of the dye. Electrical stimulation sites were identified by the iron-deposit method of passing a $20-\mu \mathrm{A}$ anodal DC current for $10 \mathrm{sec}$ through the electrode.

At the end of each experiment, the animal was sacrificed with an overdose of pentobarbital. The brain was removed, and immersed into a fixative solution composed of $10 \%$ formalin, $30 \%$ sucrose, and $1 \%$ potassium ferrocyanide for seven days to display the blue spot resulting from the iron deposit in the brain tissue. The brain tissue was frozen and sectioned into slices $50 \mu \mathrm{m}$ thickness and stained with cresyl violet.

\section{RESULTS}

\section{Knee Jerk (KnJ) and Cross Extensor Movement (CEM)}

In six cerebellum-intact cats, the effects of electrical stimulation of the three depressor areas in the caudal medulla, i.e., PRN, MRN and DMD on $\mathrm{KnJ}$ and CEM were studied. On the average, stimulation of PRN, MRN and DMD decreased MSAP 36 \pm 3 , $19 \pm 2$ and $23 \pm 3 \mathrm{mmHg}$, respectively.

Inhibition of $\mathrm{KnJ}(-93 \%)$ and CEM (-99\%) occurred when the PRN was stimulated (Table 1). Stimulation of the medial area of the rostral medulla equivalent to the position of PRN did not produce the same effect. In three of these six animals, Glu $(100 \mathrm{nl})$ 


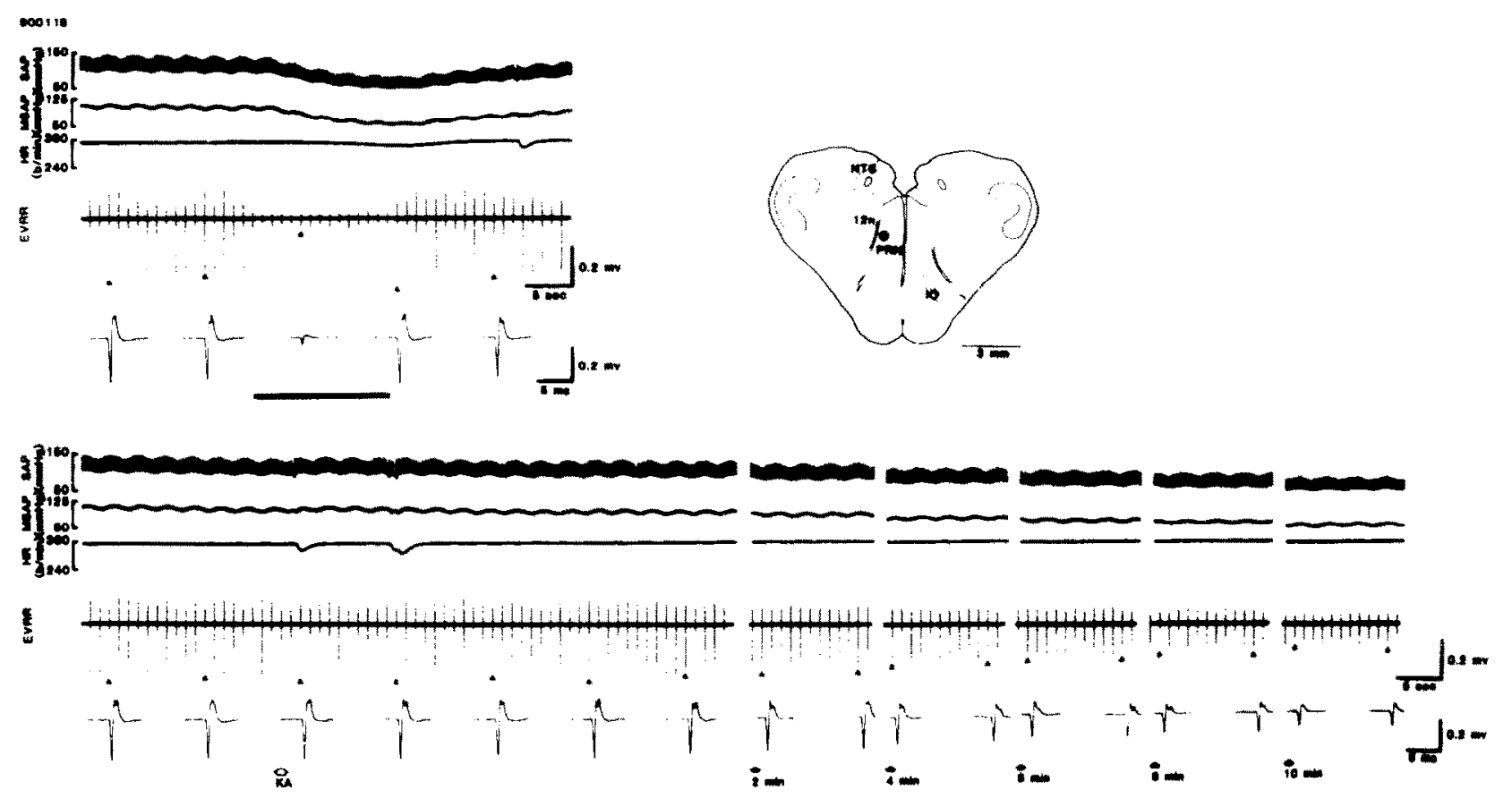

FIG. 5. Effects of kainic acid (KA) stimulation on PRN on the evoked knee jerk in a cerebellum-intact cat. EVRRs were evoked similar as Fig. 4. Dot in the histomicrograph shows the site of electrical $(100 \mu \mathrm{A}, 1.0 \mathrm{msec}$ and $80 \mathrm{~Hz}$ ) and KA stimulation (200 nl). Note the prolonged action of KA. The reduction of the EVRR persisted for $10 \mathrm{~min}$ after the application of KA. Bottom traces are the expanded EVRRs of a single EVRR from the upper trace indicated by a triangle. $\boldsymbol{A}$. For abhreviations see Fig. 1.

was injected into the same point after electrical stimulation. Glu elicited a depressor response but smaller in magnitude than that by electrical stimulation as reported previously (8), yet the $\mathrm{KnJ}$ and CEM showed no significant alternation.

Electrical stimulation of MRN or DMD also suppressed $\mathrm{KnJ}$ and CEM but to a lesser extent than that of PRN stimulation (Table 1). The inhibition from MRN stimulation was moderate: KnJ $(-70 \%)$ and CEM $(-67 \%)$. The inhibition from DMD stimulation on both $\mathrm{KnJ}$ and CEM was small and insignificant (Table 1).

In two chronically decerebellated cats, PRN stimulation also produced marked suppression of the $\mathrm{KnJ}$ and CEM.

\section{Evoked Ventral Root Responses (EVRR)}

Cerebellum-intact cats. In 29 cerebellum-intact animals, EVRRs were recorded and results are illustrated in Figs. 1-5 and summarized in Table 2.

PRN stimulation. Stimulation of the PRN produced only mild hypotension (Fig. 1, upper panels, B). When the PRN was stimulated simultaneously with tibial nerve stimulation, practically all the short- and long-latency evoked ventral root discharges (Fig. 1 upper panel Aa) were markedly reduced (Fig. 1, upper panel b). The reduction was most prominent ( $40 \%$ or more) in potential components 1,2 , and 3 . Reduction also occurred in the potential of component $4(-8 \%)$ though not statistically significant (Table 2). In eleven animals, the PRN, after electrical stimulation, was injected with Glu (100 nl), DLH (100 nl), or KA (100 $\mathrm{nl}$ ). The reduction of monosynaptic reflexes, varied from $20-80 \%$, was observed in all of these animals (Glu 2, DLH 4, kainic acid 5) with a latency of onset varying from $5 \mathrm{sec}$ to $4 \mathrm{~min}$. The duration of the reduction was most prolonged after $\mathrm{KA}$ injection. The action persisted for over 15 min (Fig. 5). The action was short with the Glu or the DLH injection, and the reflex returned to its original level 4 min after the injection (Fig. 4). In all the eleven cats showing a reflex reduction, a decrease of SAP of more than $50 \mathrm{mmHg}$ was observed only in two (see Figs. 4 and 5).

MRN stimulation. Stimulation of the MRN also produced a hypotensive response, and a much less inhibitory effect on EVRR (Fig. 2Aa, b). Among the four components of the evoked potentials, only that of component 2 was significantly reduced, but the reduction was much smaller than that following PRN stimulation, $-20 \%$ vs. $-48 \%$ (Table 2 ). The evoked potentials of components 1 and 3 were not affected. The potentials of component 4 were enhanced $(+26 \%$, Table 2$)$ rather than inhibited.

Dorsal medullary depressor area (DMD) stimulation. DMD stimulation also produced hypotension. Nevertheless, DMD stimulation produced the smallest inhibitory action on most components of the evoked potentials (Fig. $3 \mathrm{Aa}, \mathrm{b}$, Table 2); only the component 2 responses were significantly depressed $(-22 \%)$. Additionally, the inhibition was much smaller than that of the PRN ($48 \%$ ). DMD stimulation had only a slight inhibitory effect on potentials of components 1 and 3 , while in component 4 , a small enhancement occurred rather than an inhibitory effect (Table 2).

In summary, comparing the three depressor areas (PRN, MRN and DMD), PRN stimulation is the most potent one in producing a significant inhibition ( $40 \%$ or more) of the short- and long-latency EVRRs of components 1-3. Stimulation of MRN and DMD effectively inhibited the potential of component 2 but the magnitude of the inhibition $(20-22 \%)$ was much smaller than that produced by PRN stimulation. The inhibitory action of PRN stimulation on the EVRR was significantly more effective in comparison with that resulting from MRN stimulation (one-way ANOVA); whereas the differences between PRN and DMD or MRN and DMD stimulation were not statistically significant.

Chronically decerebellated cats. The EVRR was studied in eleven chronically decerebellated cats and the results are shown in Fig. 1, lower panels, and Table 2.

Similar to intact animals, PRN stimulation also produced a 
mild hypotensive response and a noticeable inhibition of $38 \%$ or more on the EVRR in components 1-3. The inhibitory effect on component 4 was only slight $(-11 \%)$. The suppression was most pronounced in the components of transmission velocities between 10 and $60 \mathrm{~m} / \mathrm{sec}$ (components 2 and 3 ). The inhibition was greater in the decerebellated than in the cerebellum-intact animals (component $2,-61 \%$ vs. $-48 \%$; component $3,-45 \%$ vs. $-40 \%$ ).

\section{DISCUSSION}

In the present study we confirm the previous findings of ours (8) and others $(5,15)$ on the cardiovascular inhibitory action of PRN. These results show that electrical stimulation of the PRN, produced marked inhibition of the $\mathrm{KnJ}$ and $\mathrm{CEM}$ induced by sciatic nerve afferents stimulation as well as the EVRR which results from stimulation of the afferent tibial nerve. Stimulation of the other depressor areas adjacent to PRN such as MRN and DMD, produced only partial inhibition of the EVRR. Also, stimulation in these areas produced facilitation rather than inhibition on component 4 of the EVRR. Therefore, the action of the PRN on spinal reflexes appears to be specific. This PRN effect does not involve a cerebellar mechanism because after chronic decerebellation the inhibition, either of the short- or long-latency EVRR, persisted.

The cerebellum is known to modulate somatic functions, including muscular tonus, postural adjustment (22), and possibly spinal reflexes (21). A direct fiber pathway has been shown to descend from the fastigial nucleus to the motor neurons in the ventral horn of the spinal cord (1). Cerebellar nuclei and PRN are closely related $(3,4,17,36,39)$. Also the cerebellum has been reported to mediate postural and cardiovascular functions together with the PRN $(19,23,35)$. This suggests that inhibition of spinal reflexes by PRN stimulation might be the result of an indirect activation of a cerebellar mechanism. Of course, during PRN stimulation in intact animals indirect action through the cerebellum might occur simultaneously. This does not appear to be the case, since in the decerebellated animals, 9-12 days after the operation, both the afferent fibers to, and efferent fibers from, the cerebellum had degenerated.

In eleven of 36 animals, when electrical stimulation of the PRN markedly decreased spinal reflexes (100\%), the PRN also responded to excitatory amino acids; a fact which suggests the existence of neuronal cell bodies in the area (24). The responses were smaller in magnitude, with decreases averaging $40 \%$ (20$80 \%$ ). These results on the PRN were in contrast to those of the pressor areas of the dorsal and ventrolateral medulla which responded to excitatory amino acids more readily in producing much greater pressor responses (9). The smaller sensitivity of the PRN to excitatory amino acids might be attributed to the fact that PRN neurons contain a smaller number of receptors for these chemicals. In view of the fact that low intensity electrical stimulation of the PRN, a restricted area of the caudal medulla, was very effective in producing marked spinal reflex inhibition, the PRN might be an area with a high density of neurons and/or fiber pathways from many sources.

Stimulation of the PRN produced marked inhibition of the vasoconstrictive pressor response. This vasodepressor action could also be induced by excitatory amino acids (8). It should be noted that chemically induced inhibition of spinal reflexes by the PRN does not necessarily at the same time produce a vasodepressor response. These might not be the same that produce inhibition of visceral and somatic functions; these might be a coexistence of neurons with separate functions in the same PRN area. Coexistence of neurons of different functions in a very small area of a nucleus in the brain is not uncommon. For instance, the lateral reticular nucleus of the ventrolateral medulla, where neurons for sympathetic cardiovascular integration reside (14) also contains neurons mediating antinociceptive action, i.e., suppression of tail-flick response (29). Stimulation of the nucleus locus coeruleus, an important site of sympathetic function (41), produced somatic effects, manifested as an increase in L5 ventral root monosynaptic reflexes evoked by stimulation of the peroneal or tibial nerve (10).

The medial area of the medulla exhibiting marked inhibition of spinal reflex resides in the territory of PRN: stereotaxic coordinates of $0-4 \mathrm{~mm}$ rostral to obex, 0.7 to $2 \mathrm{~mm}$ from the midline and 2 to $4 \mathrm{~mm}$ from the dorsal surface of the medulla. These coordinates are consistent with those reported before $(19,25)$. The area of inhibition is apparently much smaller in size than that reported by Magoun and Rhines (34), who showed inhibition of spinal reflexes by stimulation of the medial portion of the lower brain stem. They reported that this area spreads more laterally and extends even to the rostral pons despite a relative concentration in the medial portion of the caudal medulla. Inhibition of L7 ventral root monosynaptic reflexes evoked by stimulation of the gastrocnemius-soleus nerve has been achieved by stimulation of the reticular formation in the brainstem, in levels varying from the caudal medulla to the rostral pons (12). The precise boundaries of the reticular formation, however, have not been delineated.

PRN might exert its inhibitory action through the following mechanisms: (a) PRN might contain interneurons and their fibers might synapse with other neurons in the brainstem or elsewhere in the brain to subsequently inhibit motoneurons pool in the spinal cord. (b) Direct inhibition of the motoneuron pool, either through presynaptic or postsynaptic mechanisms. Llinas and Terzuolo (33) as well as Jankowska et al. (27) showed that stimulation of Magoun's inhibitory area (including PRN), prevents the monosynaptic activation of motoneurons and such inhibition is postsynaptic in nature, as the IPSP evoked in the flexor and extensor motoneurons was observed at low strength of stimulation. Presynaptic inhibition through primary afferent depolarization might possibly play a role in the pronounced and generalized motor inhibition descending from Magoun's inhibitory area, since dorsal root potentials are evoked at the strength required to generate IPSPs (27). Also, inhibition of reflex paths might be produced by processes operating at interneuronal levels $(6,20,26)$. The most likely mechanism seems to be postsynaptic inhibition of motoneurons $(27,33)$.

The present study provides evidence of supraspinal influences on spinal motoneuronal activity. These effects can be achieved in a variety of ways: (a) biphasic excitation and inhibition of both flexor and extensor motoneurons $(11,12,37,38)$; (b) suppression of both types of motoneurons $(28,32,33)$; (c) excitation of extensor and inhibition of flexor motor activities (40); and (d) facilitation of both types of motoneurons (10). In the present study, the supraspinal mechanism seems to be of the (b) type because PRN stimulation can suppress all the short- and longlatency EVRRs which contain mono- and polysynaptic spinal reflexes of both extensor and flexor. The inhibition of the short-latency component 1 EVRR might be the result of activation through the postsynaptic mechanism, while the inhibition of the long-latency reflexes (components 2, 3 and 4), might act through an indirect polysynaptic mechanism by way of different levels of spinal cord and brain structures.

Finally, in addition to a direct modulatory motor function, it is not impossible that the PRN might influence spinal reflexes by acting on somatic afferent functions, since the PRN receives various inputs from somatic afferents $(13,16)$.

In summary, the present study presents evidence that in the PRN of the caudal medulla oblongata, in addition to its potent inhibition of autonomic functions, there is an independent mechanism, which does not involve the cerebellum, for modulating somatic spinal reflexes. 


\section{ACKNOWLEDGEMENTS}

The authors thank Mr. G. T. Chen for preparation of the illustrations. Special thanks are due to Professor S. H. Ngai of Columbia University for reading the manuscript and advice. This study was supported in part by the Foundation of Biomedical Sciences, Institute of Biomedical Sciences. Academia Sinica and the National Science Council, R.O.C. No. $755327-070$

\section{REFERENCES}

1. Asanuma, C.; Thach, W. T.; Jones, E. G. Brainstem and spinal projections of the deep cerebellar nuclei in the monkey, with observations on the brainstem projections of the dorsal column nuclei. Brain Res. Rev. 5:299-322; 1983.

2. Avanzino, G. L.; Bradley, P. B.; Wolstencroft, J. H. Pharmacological and electrophysiological characteristics of neurons in the paramedian reticular nucleus. Arch. Ital. Biol. 113:193-204; 1975.

3. Brodal, A. Recticulo-cerebellar connections in the cat. J. Comp. Neurol. 98:113-153; 1953.

4. Brodal, A.; Torvik. A. Cerebellar projections of paramedian reticular nucleus of medulla oblongata in cat. J. Neurophysiol. 17:484-495 1954

5. Calaresu, F. R.; Thomas, M. R. The function of the paramedian reticular nucleus in the control of heart rate in the cat. J. Physiol. (Lond.) 216:143-158; 1971.

6. Carpenter, D.; Lundberg, A.; Norrsell, U. Primary afferent depolarization evoked from the sensorimotor cortex. Acta Physiol. Scand. 59:126-142; 1963

7. Chai, C. Y.; Lee, T. M.; Wayner, M. J. Effect of visceral afferent activation on leg extension induced by sciatic afferent stimulation. Brain Res. Bull. 3:115-123; 1978.

8. Chai, C. Y.; Lin, Y. F.; Lin, A. M. Y.; Pan, C. M.: Lee, E. H. Y. Kuo, J. S. Existence of a powerful inhibitory mechanism in the medial region of caudal medulla - with special reference to the paramedian reticular nucleus. Brain Res. Bull. 20:515-528; 1988.

9. Chai, C. Y.; Lin, R. H.; Lin, A. M. Y.; Pan, C. M.; Lee, E. H. Y. Kuo, J. S. Pressor responses from electrical or glutamate stimulation of the dorsal or ventrolateral medulla. Am. J. Physiol. 255:R709R717; 1988.

10. Chan, J. Y. H.; Fung, S. J.; Chan, S. H. H.: Barnes, C. D. Facilitation of lumbar monosynaptic reflexes by locus coeruleus in the rat. Brain Res. 369:103-109; 1986.

11. Chan, S. H. H.; Barnes, C. D. Postsynaptic effects evoked from brainstem reticular formation in lumbar cord and their temporal correlations with a presynaptic mechanism. Arch. Ital. Biol. 112: 81-97; 1974

12. Chan, S. H. H.; Barnes, C. D. A presynaptic mechanism evnked from brainstem reticular formation in the lumbar cord and its temporal significance. Brain Res. 45:101-114; 1972.

13. Chelarducci, B.; Pompeian, O.; Spyer, K. M. Macular input to precerebellar reticular neurones. Pflugers Arch. 346:223-231; 1974.

14. Ciriello, J.; Caverson, M. M.; Polosa, C. Function of the ventrolatera medulla in the control of the circulation. Brain Res. Rev. 11:359-391; 1986.

15. Coote, J. H.; Macleod, V. H. The spinal route of sympathoinhibitory pathways descending from the medulla oblongata. Pflugers Arch. 359:335-347; 1975

16. Duggan, A. W.; Game, C. J. A. Spontaneous and synaptic excitation of paramedian reticular neurones in the decerebrate cat. J. Physiol (Lond.) 247:1-24; 1975 .

17. Elisevich, K. V.; Hrycyshyn, A. W.; Flumerfelt, B. A. Axonal branching in the projections from the paramedian reticular nucleus to the cerebellar cortex. Neurosci. Lett. 52:195-200; 1984

18. Elisevich, K. V.; Hrycyshyn, A. W.; Flumerfelt, B. A. Cerebellar, medullary and spinal afferent connections of the paramedian reticular nucleus in the cat. Brain Res. 332:267-282; 1985.

19. Elisevich, K.; Ciriello, J. Cardiovascular afferent and fastigial nucleus inputs to paramedian reticulospinal neurons. Brain Res. 452:141-148; 1988.

20. Engberg, I.; Lundberg, A.; Ryall, R. W. Reticulospinal inhibition of transmission in reflex pathways. J. Physiol. (Lond.) 194:201-223; 1968 .

21. Ganong, W. F. Review of medical physiology. 13th ed. CT: Appleton and Lange Publication; 1987:181.

22. Ghelarducci, B. Responses of the cerebellar fastigial neurons to tilt. Pflugers Arch. 344:195-206; 1973.

23. Ghelarducci, B.; Pompeiano, O.: Spyer, K. M. Activity of precerebellar reticular neurones as a function of head position. Arch. Ital. Biol. 112:98-125; 1974.

24. Goodchild, A. K. R.; Dampney, R. A.; Baandler, R. A method for evoking physiological responses by stimulation of cell bodies, but not axons of passage, within localized regions of the central nervous system. J. Neurosci. Methods 6:351-363; 1982.

25. Homma, S.; Miura, M.; Reis, D. J. Intracellular recording from paramedian reticular neurons monosynaptically excited by stimulation of the carotid sinus nerve. Brain Res. 18:185-188; 1970.

26. Hugelin, A.; Dumont, S. Controle reticulaire du reflexe linguo-maxillaire et des afferences somesthesiques. J. Physiol. (Paris) 52:119$120 ; 1960$.

27. Jankowska, E.; Lund, S.; Lundberg, A.; Pompeiano, O. Postsynaptic inhibition in motoneurones evoked from the lower reticular formation. Experientia 20:70; $-702 ; 1964$.

28. Jankowska, E.; Lund, S.; Lundberg, A.; Pompeiano, O. Inhibitory effects evoked through ventral reticulospinal pathways. Arch. Ital. Biol. 106:124-140; 1968.

29. Janss, A. J.; Box, B. F.; Brody, M. T.; Gebhart, G. F. Dissociation of antinoceptive from cardiovascular effects of stimulation in the lateral reticular nucleus in the rat. Brain Res. 405:140-149; 1987

30. Leontovich, 'T. A.; Zhukova, F. P. The specificity of the neuronal structure and topography of the reticular formation in the brain and spinal cord of carnivora. J. Comp. Neurol. 121:347-379; 1963.

31. Lin, A. M. Y.; Pan, C. M.; Lin, Y, F.; Kuo, J. S.; Chan, S. H. H.: Chai, C. Y. A cardioinhibitory area in the midbrain central tegmental field of cats. Brain Res. Bull. 18:699-707; 1987

32. Llinas, R.; Terzuolo, C. A. Mechanisms of supraspinal actions upon spinal cord activities. Reticular inhibitory mechanisms on alpha-extensor motoneurons. J. Neurophysiol. 27:579-591; 1964.

33. Llinas, R.; Terzuolo, C. A. Mechanisms of supraspinal actions upon spinal cord activities. Reticular inhibitory mechanisms upon flexor motoneurons. J. Neurophysiol. 28:413-423; 1965.

34. Magoun. H. W.; Rhines, R. An inhibitory mechanism in the bulbar reticular formation. J. Neurophysiol. 9:165-171; 1946.

35. Miura, M.; Reis, D. J. A blood pressure response from fastigial nucleus and its relay pathway in brainstem. Am. J. Physiol. 219:1330$1336 ; 1970$.

36. Miura, M.; Reis, D. J. The paramedian reticular nucleus: a site of inhibitory interaction between projections from fastigial nucleus and carotid sinus nerve acting on blood pressure. J. Physiol. (Lond.) 216: $441-460 ; 1971$

37. Sasaki, K.; Tanaka, T. Phasic and tonic innervation of spinal alpha motoneurons from upper brain centers. Jpn. J. Physiol. 14:56-66; 1964.

38. Shapovalov, A. I.; Gurevitch, N. Monosynaptic and disynaptic reticulospinal actions on lumbar motoneurons of the rat. Brain Res. 21: $249-263 ; 1970$.

39. Somana, R.; Walberg, F. Cerebellar afferents from the paramedian reticular nucleus studied with retrograde transport of HRP. Anat. Embryol. (Berl.) 154:353-368; 1978.

40. Sprague, J. M.; Schreiner, L. H.; Lindsley, D. B.; Magoun, H. W. Reticulospinal influences on stretch reflexes. J. Neurophysiol. 11: 501-507; 1948

41. Virginia, K. W.; Palkovits, M.; Kopin, I. J. Effect of ventral noradrenergic bundle transection and locus coeruleus lesions on urinary 3-methoxy-4-hydroxyphenylethyleneglycol (MHPG) excretion in the rat. Brain Res. 359:239-245; 1985. 